\title{
Theory of Connectivity as an Emergent Solution to Innovative Learning Strategies
}

\author{
Ingrid del Valle García Carreño* \\ Faculty of Education and Teacher Training, Autonomous University of Madrid (AUM), Madrid, Spain \\ *Corresponding author: 5133871@gmail.com
}

Received February 03, 2014; Revised February 13, 2014; Accepted February 21, 2014

\begin{abstract}
Faced with globalization and the inclusion of the Internet in the educational process, new dilemmas have emerged. In response, innovative theories of learning must be born and the teacher should create different strategies and prepare new skills. So far, all learning theories have focused on classroom attendance and so teaching and evaluation strategies, but in the XXI century there arises the need to develop other skills and styles such as elearning, e-portfolio, e-blog among others. While there is talk of student-based learning and collaboration, it should be kept in mind that at the time those theories were formed present technologies did not exist. Technology has created and defined a new culture, reshaping the way we communicate study and learn. With this phenomenon, the need arises to create a new theory which can adapt to these changing circumstances. This emerging theory is the theory of connectivity. The purpose of this paper was to prepare and explain following topics: first of all the paradigms of education as presage, product, process-product, mediational and contextual or ecological paradigm. Secondly, the theories of education before connectivity: behaviorism, cognitive, historical- social and constructivism. As third point, we development the principles elements of connectivity, as an emergent solution to innovative elearning. Such as last point we present reflections and conclusions
\end{abstract}

Keywords: complex thought, Connectivity Paradigms, education theories, networks, nodes

Cite This Article: Ingrid del Valle García Carreño, "Theory of Connectivity as an Emergent Solution to Innovative Learning Strategies.” American Journal of Educational Research, vol. 2, no. 2 (2014): 107-116. doi: 10.12691/education-2-2-7.

\section{Introduction}

The Internet, as a learning tool, has based in three theories: constructivism, conversation and situated knowledge [1]: (i) Theory of conversation: Internet adheres to the Vygotskian notion of interaction among people who bring different levels of experience to a technological culture; Internet is an environment that requires a specific social nature and a process whereby learning creates a virtual area, the zone of proximal development (ZPD) that also is considerate in the computer-assisted instruction (CAI). (ii) Theory of the situated knowledge: The Internet environment responds to the premises of the situated knowledge in two of its characteristics: Realism and complexity. The Internet facilitates authentic interchanges among users who belong to different cultural contexts, but with similar interests, and the unstable nature of the Internet becomes a stumbling block for the non-initiated, who, nonetheless, and due to their peripheral participation, are rewarded with a gradual cultural insertion Finally, (iii) Constructivism: in education there are debates associated with behaviorism and constructivism, which is reflected in the universities at the time of design and implementing a virtual classroom. Before this controversy it is recommended to use a mix strategy to implement in the virtual classrooms where the advantages of both perspectives are used.

In fact, behaviorism, cognitivist, and constructivism are the three broad learning theories most often used in order to design 4instructional environments. We must understand that these theories were developed in a time when learning was not impacted through technology. It is true that over the last twenty five years, technology has reorganized how we communicate, and how we learn. Learning needs and theories that describe learning principles and processes should be reflective of underlying social environments.

Another important issue is that central theory of most learning models is that learning occurs inside a person. Even social constructivist views, which hold that learning is a socially ratified process, stimulate the principality of the individual (i.e. brain-based) in learning. These three theories (behaviorism, cognitivist, and constructivism) do not address learning that occurs outside of people (i.e. learning that is stored and manipulated by technology). We look and motived for learning theories as a concerned with the actual process of learning, not with the value of what is being learned.

Too many questions are raised when established actual learning theories are seen through technology, in order to explore in relation to learning theories and the impact of technology and new sciences (chaos and networks) on learning: What is the impact of networks and complexity 
theories on learning? What is the impact of chaos as a complex pattern recognition process on learning?

In this research, the theory of connectivism will be exposed as a completely new emerging model of learning. The connectivism is the integration of principles explored by chaos, networks, complexity and self-organization theories; it is focused on connecting specialized information sets, and the connections that allow us to learn. In an information society where there are so many changes, this theory is oriented by decisions taken before the new principles and new information.

\section{Paradigms of Education}

The paradigms of education are within the psychology of education that is a discipline in which coexist several alternative paradigms, that is a discipline with different paradigms. Paradigm is defined as configuration of beliefs, methodological values and theoretical assumptions that share a specific community of researchers [2,3].

Paradigms are universally recognized scientific achievements that provide models of problems and solutions to a scientific community for some time. Each scientific community shares a same paradigm and when it is posed again, it enters crisis and is when given the scientific revolution. The continuous cycle of breakdown and acceptance of new paradigms is what creates the scientific knowledge.

Contrary: [4], explains the progress of the science not by ruptures but by a continuous suppression of errors and further tests; these are the concepts of falsification in the Darwin's context about evolutionary epistemology of knowledge. "Every scientific discussion begins with a problem (P1) that we offer some tentative solution - a tentative theory (TT); then this theory is subjected to criticism in an attempt to eliminate error (EE), and as in the case of the dialectic, this process renews itself: the theory and its critical review creates new problems (P2). [5] argues that in the practice different paradigms coexists without result in abandonment or death of the previous paradigm.

The current literature about educational research exposes four fundamental paradigms: positivist [6,7]; interpretive [8], critical-reflective [9] and recently the emerging paradigm [10] supported by many authors like. This emerging paradigm, in process of construction, is a possibility of integration with its own characteristics.

[11] are anticipated to ensure next generation of researchers (referring to the field of educational evaluation), will be beneficed in all traditions: "...these researchers can use the widest possible range of methods and without stinginess they will accommodate techniques to the problems of research." They will learn new ways to combine the methods and also, how to accept new discrepant discoveries without to reject a group in favor of another". Modesty in the statements will be a characteristic of the researchers. The disadvantage of a method will not be cause to abandon it but a challenge to overcome it. The task will not be easy but it is worth assume it.

The creation of global models for understanding and improving teaching-learning processes has been a lively field for empirical research, with abundant research contributions over the 20th century and continuing today. Several lines of research have produced findings and contributions. Each of these groups begins historically with different concerns and focuses of interest, although it is not easy to establish strict boundaries between them or between the topics that describe their sequencing and evolution over time. These groups have been characterized in the literature under the founding labels: the presageproduct paradigm, the process-product paradigm, the student-centered mediational paradigm, the mediational paradigm centered on teacher decision making, and the ecological paradigm.

[8] says: Research studies based on these paradigms have been produced and continue to be produced in parallel. And not even today can we affirm that one of these paradigms has become definitively established as the winning paradigm. Educational science is at an earlier stage, prior to configuration of theories and consolidation of paradigms Nonetheless, it is possible to affirm that the presage-product paradigm is no longer in force and the process-product paradigm has received so much criticism and has had to produce so many "ad hoc" explanations and be reformulated so often that it also appears to be exhausted, or unrecognizable, as a paradigm.

To this point authors as [12,13,14] develop three models: (i) presage-product, (ii) process-product and (iii) teacher's thinking or mediational.

Presage-product, pretends to find relationship between the behavior of the teachers while they teach (process), and the improvements that students demonstrate in their learning (product) as consequence of the experimentation and the action of the teacher. The teaching efficiency in this model will depend of the teacher's behavior, assuming a great importance the act. The importance of the personal characteristics is showed in many studies. Nowadays, this model has evolved and has been reformulated to the study of constructs such as values, attitudes, interests, self-concept and self-esteem, etc.

Process-product, puts the emphasis in the study of the teacher's behavior in the classroom and the results of the learning that students get [12], reviews different research that show that the personality is not what makes efficient at the teacher but the mode of proceeding, highlighting aspects as the teacher's expectations and their expectations about the students: the pleasant climate class, the settlement context and direct aid to students, the progression of the task ensuring the probability of success, the active teaching, the teaching that leads to over learning at each of the stages of the instructional course, etc.

The mediational, is based on the theory of processing of information and based on the assumption that the teacher is a reflective professional who makes decisions and whose thoughts guide and direct their conduct. The studies of this line of research have shown the influence of aspects such as the experience of the teacher and the matter or content offered in planning and teaching performance. An interesting aspect of this model is the possibility of awareness of the teacher of their own beliefs and actions. However, one of the problems is the lack of consideration of the beliefs or theories that the teacher has about himself or other aspects of the educational reality different to the students or specific ways of teaching.

New generation models that integrate the Presage, Process and Product variables, the Biggs 3P model (2005) 
starts from the assumption that students use certain learning strategies as a function of the motives they have for learning, these being one of the central determinants of the teaching-learning process. Under this structure, students undertake actions and carry out tasks as a function of what they think will contribute to greater academic success and will be rewarded by the system, as a function of the motives that have prompted their learning.

This requires that the teacher be aware that each student is pursuing a different path in his/her learning process, and that these paths are closely related to the reasons that prompt students to find successful solutions.

New generation models that integrate the Presage, Process and Product variables, the Biggs 3P model starts from the assumption that students use certain learning strategies as a function of the motives they have for learning, these being one of the central determinants of the teaching-learning process. Under this structure, students undertake actions and carry out tasks as a function of what they think will contribute to greater academic success and will be rewarded by the system, as a function of the motives that have prompted their learning.

This requires that the teacher be aware that each student is pursuing a different path in his/her learning process, and that these paths are closely related to the reasons that prompt students to find successful solutions Figure 1.

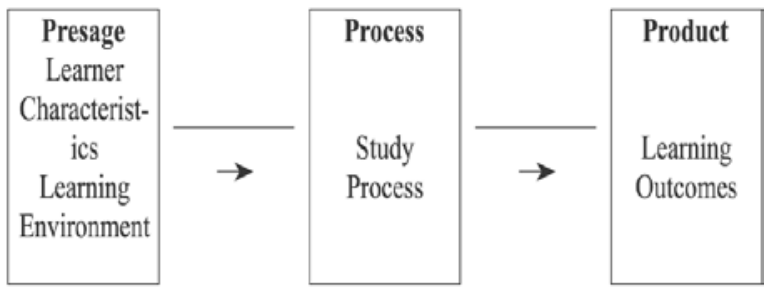

Figure 1. The Biggs 3P model

Mediational paradigm appears to coincide with the rise of cognitive psychology and constructivism, from the decade of the seventies. In this paradigm the teacher's ability to process, organize and communicate information stands. In this sense, advocates that is the mind which directs to the person and not external stimuli (behaviorism) or the irrational stimuli (psychoanalysis). How [15]: “...cognitive psychology, although part of a traditional study in psychology, the mental life, the mental process, the mind in one word, made it from a consideration of this object. The mind is considered as a system and its operation as a computational system that manipulates the information. (p. 20)”. For that, “...the conduct in an educational fact is not a priority; from now on the psychological process will support such behavior" [15].

Contextual or ecological paradigm: to the characteristics of the mediational paradigm, adds the component of the environment, it gives more importance to qualitative research than to quantitative research and, finally, it insists in the study of life in the classroom. For this reason, according to some authors, this paradigm has taken the teacher's training to become in a researcher in the classroom [15].

\section{Theories of Education}

Before dealing with the theory of the connectivity, it is essential to know the characteristics that underlie the different theories of education because this allow to understand what has happened in the education and where it goes, it allows us to understand the methodological approach, the strategies of learning used, etc.

As a frame of reference for educational paradigms, we will analyze the essential characteristics of the most representative paradigms according to cognitive psychology: the behaviorism, the cognitivism, the historical-social, and the constructivism. Constructivism will be addressed as a theory that emerges from the cognitivism and from the historical-social paradigm to take two aspects: the social constructivism and the psychological constructivism, which is very present today [16].

\subsection{Behaviorism Paradigm}

The behaviorism emerges as a psychological theory and then its use is adapted in the education, it becomes the first theory that comes to strongly influence the way how human learning is understood. Before the rise of behaviorism, the learning was conceived as an internal process and it was investigated through a method called "introspection" in which asked people to describe what they were thinking. Behaviorism emerged as a rejection of the method of "introspection" and with a proposal for an external focus, in which measurements are made through observable phenomena. (J.B. Watson (1920), Pavlov (1926), Thorndike (1903), F. Skinner (1904-90)). The behaviorism principles can also be applied effectively in the training of adults for certain jobs, where the "stimulusresponse" preparation is useful and even essential.

Conception of the student from the behaviorism paradigm. The student is seen as a subject whose performance and scholar learning can be arranged or rearranged from the outside (the instructional situation, methods, contents, etc.), just properly programming educational inputs to achieve learning of desirable academic behavior. Otherwise in the conception of the master from the behaviorist paradigm, the master's work consists of developing a proper series of contingency of reinforcement and stimuli control to teach [2].

\subsection{Cognitive Paradigm}

The student is active processor information who has cognitive competence to learn and resolve problems: at the same time, this competence must be considerate and developed using new learning and strategic abilities. Cognitive approach studies arise at the beginning of the 1960s and are presented as the theory that replaces behavioral prospects who had hitherto led psychology [17]: “... this cognitive theory provides great contributions to the study of the learning and teaching process, like the contribution to the exact knowledge of some essential abilities for the learning, such as the attention, memory and reasoning”. The theory shows a new vision of the human being considering it as an organism that makes an activity based mainly on the processing information, very different from the simplistic and reactive vision which, until then, had defended and released the behaviorism.

Conception of the student from the cognitive paradigm. The student is an active processor information who has cognitive competence to learn and resolve problems: at the same time, this competence must be considerate and 
developed using new learning and strategic abilities [17]. In the Conception of the teacher from the cognitive paradigm, the teacher is based on the idea that an active student who learns significantly, is able to learn to learn and think. The teacher focuses on the development and organization of didactic experiences to achieve those purposes. It must not play the leading role to the detriment of the cognitive participation of students [2].

\subsection{Historical-Social Paradigm}

Also called paradigm socio-cultural or historicalcultural, was developed by L.S. Vigotsky from 1920's. Although Vigostky developed these ideas many years ago, it is only until a few decades ago when really these were known. For the followers of the historical-social paradigm, [18]: "although the individual is important, is not the only variable in the learning. His personal history, his social class and consequently his social opportunities, his historical time, the tools he has at his disposal, are variables that not only support the learning but also are fundamental part of him", these ideas make different this paradigm of others.

The zone of proximal development (ZPD) Vigostky defines it as follow: “...the distance between the actual level of development, determined by the ability to independently solve a problem, and the level of potential development, determined through the resolution of a problem under the guidance of an adult or in collaboration with another more capable partner". Vigotsky sees in the human imitation a new $<<$ construction two $>>$ between the imitative ability of the child and its intelligent use instructed by an adult in the ZPD, thus, the adult provides at the authentic external higher psychological functions that are allowing him to achieve higher levels of complexity. Thus that, what the child can do today with help from an adult, get do it tomorrow by himself [18], [19].

Conception of the student from the historical-social paradigm. The student is to be understood as a social being, product and star of multiple social interactions in which he is involved throughout his school and extracurricular life [18].

Conception of the teacher from the historical-social paradigm. The teacher should be understood as a cultural agent who teaches in a context of practices and culturally specific media not an essential mediator between the socio-cultural knowledge and appropriation processes of students [18]. The teacher should try in his teaching the creation and construction of the ZPD with the students by means of the structure of flexible and strategic scaffolding systems.

\subsection{Constructivism Paradigm}

The constructivism is a position shared by different tendencies of the psychological and educative research. Among them are the theories of Piaget (1952), Vygotsky (1978), Ausubel (1963), Bruner (1960) and although none of them was named as constructivist, their ideas and proposals illustrate the ideas of this current. In first place, the constructivism is an epistemology; it means that is a theory that tries to explain which the nature of the human knowledge is. The constructivism assumes that nothing comes from nothing. That is to say that prior knowledge gives rise to new knowledge. The constructivism affirms that learning is essentially active. A person, who learns something new, incorporates it to their previous experiences and their own mental structures. Each new information is assimilated and deposited in a knowledge and experiences network that exist previously in the person, as result we can say that learning is neither passive nor objective, on the contrary it is a subjective process that each person is constantly changing in the light of their experiences[20].

This is the new role of the student, an essential role for his own training, a role that is impossible to give up and that will provide you with an infinite number of significant tools that will be tested in the course of their own and personal future.

Next, Piaget with the "psychological constructivism" and Vygotsky with the "social constructivism".

The constructivism of Piaget or psychological constructivism. From the perspective of the psychological constructivism, the learning is essentially a personal. There is the individual with its quasi-omnipotent brain generating hypotheses, using inductive and deductive processes to understand the world and putting to test these hypotheses with personal experience. The motor of this activity is the cognitive conflict. A mysterious strength called "desire to know" irritates us and pushes us to find explanations for the world around us. This means that in any constructivist activity should exist a circumstance that make shake the previous structures of knowledge and forcing a realignment of the old knowledge to assimilate the new. Thus, the individual learns to change their knowledge and beliefs of the world to set the new discovered realities to build their knowledge. Typically, in situations of academic learning, should to exist learning by discovery, experimentation and manipulation of concrete realities, critical thinking, dialogue and continuous questioning. Behind these activities lies the assumption that every individual, in any way, be able to build their knowledge through such activities.

The constructivism of Vigotsky or social constructivism. In this theory, also called situated constructivism, the learning has a bold interpretation: only in a social context the significant learning is achieved. It means, contrary to what is in the Piaget's theory that is not the cognitive system what makes meanings but the social interaction. The social interchange generates interpsychological representations that, eventually, must be transformed into intrapsychological; these latter representations are the structures that spoke Piaget. The social constructivism does not deny any representations of the psychological constructivism, however, considerate that is incomplete. Basically, what happens in the mind of the individual is a reflection of what happened in the social interaction [20].

There is a probabilistic important element in social constructivism. It does not deny that some individuals can be more intelligent than others. This means that in the same circumstances some individuals build mental structures more efficient than others. But for the social constructivism, this difference is secondary when it is compared with the power of the social interaction. The mental construction of meanings is highly unlikely if there is no an external scaffolding given by a social agent. To achieve its constructivist's functions, the mind not only needs of itself but also the social context that supports it. 
In summary, the mind has marked with indelible ink the parameters of thoughts imposed by a social context.

\subsection{Complex Thought Paradigm}

The theories of complexity developed in many disciplines -such as physics, biological sciences, mathematics, or socio-cultural sciences, by studying the theory of connectivity was evident that it is related to the complex. The principles upon which [21], builds what could be the complexity paradigm are three:

- the principle of organizational recursion;

- the dialogic principle and

- the hologramatic principle.

Starting from cybernetics, systems theory, theory of information, self-organization in biology and the order from noise, (Von Foerster), [21] builds a paradigm of complexity, a method: the complex thought. There are several assumptions that seek to explain: Why does appear complex thinking?

- This aims to dispel the apparent complexity of phenomena in order to reveal the simple order, to which they obey.

- Over the last three centuries have acquired knowledge about the world based on the methods of empiric and logical verification. Errors resulting from crippling mode of organization of knowledge unable to recognize and comprehend the complexity of the real also have progressed.

- The modern scientist knowledge Works trough the selection of significant data and reject what are not important: separates (distinguished) and unites (Associates), categorizes and centralizes.

- These operations are commanded by paradigms.

By excellence, the scientist paradigm is of the simplification, which is governed by the principles of disjunction, reduction and abstraction and formulated by Descartes, who separated the thinking subject and the extended thing, separating the philosophy of science [21]. This paradigm has allowed a huge progress of the scientist knowledge and of the philosophical reflection since the century XVII [21].

What is the complexity? At first sight the complexity is a tissue of heterogean (complexes: what is woven together) of inseparably associated heterogeneous constituents: presents the paradox of the one and the multiple. To look at more closely, the complexity is a tissue of events actions, interactions, feedbacks, decisions, hazards that constitute our phenomenal world. So that complexity is presented with the disturbing features of the tangled, confuse, disorder, ambiguity, uncertainty. For that is necessary for the knowledge to order the phenomena rejecting the disorder, discard the uncertain, i.e., select the elements of order and certainty, to remove ambiguity, clarify, distinguish and rank. But those operations, necessaries for the intelligibility, are in risk to produce blindness if they eliminate the others characters of the complex, and, indeed, as I have already indicated, we have become blind. But the complexity has returned to the science by the same pathway by which was gone. The development of physical science, dealing with reveal the order of the world, its perfect and absolute determinism, its obedience to a single law and its constitution of a simple primordial matter (the atom), it has finally opened to the complexity of real. It has been discovered in the physic universe a hemorrhagic principle of degradation and disorder (second law of thermodynamics); then, in the place of physical and logical simplicity, it has been discovered the extreme complexity microphysics; the particle is not a primary brick, but a border on the perhaps inconceivable complexity; the cosmos is not a perfect machine, but a process in process of disintegration and, at the same time, of organization. Finally, it is evident that the life is not a substance but a phenomenal of auto-eco organization extraordinarily complex that produces the autonomy [21].

“...the emergence of processes, facts, and multireferential, multi-dimensional and interactive objects (retroactive and recursive) and with components of randomness, chance and indeterminacy, that comprising in its apprehension irreducible degrees of uncertainty..." [21].

The emergence of complexity in science allowed to turn in the understanding of this term, which even led to the need to rethink the same dynamics of knowledge and understanding. The complexity appeared at the beginning as a sort of hiatus, confusion and difficulty. There are, indeed, many types of complexity; there are the complexities that are mainly linked to logical contradictions and complexities linked to the disorder.

The complex thought is the answer of the spirit to the fragmentation and dispersion of knowledge that can not cope with the emergence of complex phenomena. The complex thought is a thought that relates, an art thinking and a strategy of the spirit face the paradox that animates the current context that globalizes and at the same time fragments. The complex thought makes the rearticulating of the knowledge trough the application of its criteria or strategic and generative principles of its method. These are: systemic or organizational principle, principle hologramatic, principle of retroactivity, principle of recursion, autonomy/dependency principle, principle Dialogic and principle of reintroduction of the Knower in all knowledge. In this way, the purpose of the complex thought is, at the same time, to join (contextualize and globalize) and to assume the challenge of the uncertainty [21]. How? Then four principles-guidelines for thinking about complexity are outlined: these principles are complementary and interdependent:

Systemic or organizer: Joins the knowledge of the parties to knowledge of the whole, according to the formula stated by Pascal: "It is impossible know everything without knowing the parts and know the parts without knowing the whole". The systematic idea, contrary to the idea reductionist, is that "the whole is more than the sum of its parts". From the atom to the star, from bacteria to man and society, the organization of the whole produces qualities or new properties in relation to the parts considered alone: the emergencies. Thus, the organization of living things produces qualities unknown to the level of their physical-chemical constituents. Let's add that the whole is equally less than the sum of the parts, whose qualities are smothered by the organization of the whole.

Hologramatic: Inspired in the hologram where each point contains the almost all of information of the object that represents, reveals the apparent paradox of complex systems where not only the parts are on the whole, but the whole are enrolled in parts. Thus, each cell is a part of 
whole - global organism - but the whole is itself in the part: the entire genetic heritage is present in each individual cell; society is present in each individual through their language, their culture, and their rules.

Retroactivity: introduced by Norbert Wiener, it allows the understanding of the processes of self-regulation. It breaks with the principle of lineal chance: the cause acts on the effect, and the effect acts on the cause, like in a heating system where the thermostat regulates the functioning of the boiler. This regulator mechanism allows the autonomy of a system, for example, thermal autonomy of an apartment in relation to the outside cold. In a more complex way, the "homeostasis" of a living organism is a set of regulator processes founded on multiple feedbacks. The retroactivity (or feedback) allows, in a negative way, reduce deviations and stabilize a system. In the positive way, the feed-back is an amplifier mechanism, for example, in the case of the increase in tension in a conflict: the violence of a player causes a backlash which, in turn, causes another even more violent! Inflationist or stabilizers, the feedbacks are legions in the economic, social, political, or psychological phenomena [21].

\section{Theory of Connectivity}

\subsection{Backgrounds}

[22] defines learning as "a persistent change in performance or performance potential... [which] should occur as one of the results of the experience of the apprentice and the interaction with the world" (p.11). Be noted that this definition encompasses many of the attributes usually associated with behaviorism, cognitivism, social and constructivism, in particular, learning as a State of lasting change (emotional, mental, physiological (e.g.: skills) made as a result of the experiences and interactions with the content or with other people) that explores some of the difficulties to define learning.

Theories of learning set out above say that knowledge is a purpose (or an affirmation) that is attainable (if it is not innate) through reasoning and experiences. Behaviorism, cognitivism, and Constructivism (built on traditions epistemological) pretend to know how people learn [23].

Behaviorism and cognitivism see the knowledge as something extern to the apprentice, and the learning process as the act of internationalization of knowledge. Constructivism assumes that the apprentices are not empty recipients that we have to fill of knowledge. Instead, the apprentices try to create meanings in an active way. Often, the apprentices select and seek their own learning. The constructivist principles admit that learning in a real life is confused and complex. The classrooms that emulate the "ambiguity" of this learning will be more effective at the moment to prepare to the apprentices for the learning throughout their life [22].

\subsection{Limitations of Behaviorism, Cognitivism and Constructivism}

The main dogma of many of the learning theories is that learning occurs within the people. Even the views of social constructivism, which affirms that learning is a socially established, promote the primacy of the individual in learning. The theories studied so far do not consider the learning which takes place outside people. There is also a weakness in describing how learning takes place within systems. They refer to the process of real learning, not the value of what is learned.

In a network world, it is worth exploring the information that we acquire. The need to assess the value of learning something is a goal-ability that applies before starts the learning in itself. When the knowledge is scarce, it is assumed the process of evaluation of the value is intrinsic to learning. When knowledge is abundant, the quick assessment of knowledge is important. Additional concerns arise because of the rapid increase in information.

When the learning theories preset are considered along with the technology, arise many important questions. The natural attempt of the theorists is to continue reviewing and developing theories, since the conditions change. At some point, however, the underlying conditions have been altered so significantly, that it is not sensible to make more modifications. Is necessary a completely new approach.

\subsection{Connectivity as Alternative Theory}

Including the technology and the construction of connections as learning activities, the learning theories in fact begin to move in a digital age. Already we cannot experience personally and acquire the learning that we need to act. We deduce our skill to make connections.

[24] affirms: "The experience for a long time has been considered the best teacher of knowledge. Since we cannot experience everything, the experience of other people, and as consequence those people, become the substitute for the knowledge. 'I store my knowledge in my friends' is an axiom for collecting knowledge through collecting people (undated) [25].”

Chaos theory can be defined as "the qualitative study of unstable aperiodic behavior in deterministic non-linear dynamical systems [26]. It is a part of complexity theory which concerns itself with non-linear dynamic systems whose behavior does not follow clearly predictable and repeatable pathways. In linear systems, the relationship between an environmental factor and system behaviour is predictable and easily modelled.

As the presence of an environmental factor increases, the system behavior changes linearly in response to it. In contrast, behaviour in chaotic systems may be perceived as unpredictable, the systems explored in chaos theory are dynamic.

Organizational change resulting from information system implementation must result from interactions between actors, whether human or machine, within the organization. Information, values, processes and behavior are transmitted through relationships which, hopefully, add value to the organization. An organization may be viewed as consisting of a network of relationships, which are supported by information systems [27]. Within these networks, subcultures or communities-of-practice may exist [28]. The interactions within these relationships provide dynamic networks of connection that support knowledge flow, enable the spread of socialization and encourage the growth and death of concepts, ideas and values [25]. 
[28] said about generation of feedback: they also support it, correspondingly amplifies particular views, initial conditions and strategies that may already be present in a small way. The vast complexity of these networks of connection within the organization gives rise to chaotic behaviour, cyclical patterns and strange attractors. The complex networks of interaction support emergent behaviour which cannot easily be reduced to a simple set of influencing factors and is inherently uncertain and unpredictable. Exploring connectivity may be an important element of an interpretive framework using chaos theory as its foundation

Chaos is a new reality for knowledge workers. [29] definition about what is the chaos "a cryptic form of order". Chaos is the breakdown of predictability, evidenced in complicated configurations that initially attack against order. Unlike with constructivism, which states that apprentices try to promote the knowledge by giving meaning to the tasks that they make, chaos theory states that the meaning exists and the apprentice's challenge is to recognize the patterns which appear to be hidden.

[30] learning, as a process of self-organization, requires that the system (personal or organizational learning systems) "is informational open, i.e., that it serves to classify its own interaction with an environment, should be able to change its structure..." (p.4).

The self-organization on a personal level is a microprocess of creation of self-organization theories larger of knowledge, created within corporate or institutional environments. To learn in our knowledge economy, it is necessary the ability to make connections between information sources and, accordingly, to create models of useful information. [30]: taking this approach even further is [29]: "We derive our competence," writes [29]: "from forming connections... Chaos is a new reality for knowledge workers... Unlike constructivism, which states that learners attempt to foster understanding by meaningmaking tasks, chaos states that the meaning exists... the learner's challenge is to recognize the patterns which appear to be hidden. Meaning-making and forming connections between specialized communities are important activities."

The Chaos and adaptive networks and as a science, recognizes the connection of everything to everything. Unlike constructivism, which states that learners attempt to foster understanding by meaning making tasks, chaos states that the meaning exists - the learner's challenge is to recognize the patterns which appear to be hidden.

Networks are adaptive: they constantly adjust and transform in reaction to the world around. Nodes within the network continually update themselves, accruing ongoing benefit to the entire structure. In a sense, we can see this phenomenon in the field of human knowledge growth over the last half-century. The dramatic advancements of science and society can largely be attributed to the increased capacity of people and organizations to connect with each other.

Meaning-making and forming connections between specialized communities are important activities. Chaos is the breakdown of predictability, evidenced in complicated arrangements that initially defy order. This highlights a real challenge: "sensitive dependence on initial conditions” profoundly impacts what we learn and how we act based on our learning. Decision making is indicative of this. If the underlying conditions used to make decisions change, the decision itself is no longer as correct as it was at the time it was made. The ability to recognize and adjust to pattern shifts is a key learning task.

Networks, small worlds, weak links. A network can be defined simply as connections between entities. The computer networks, energy networks and social networks works on the simple principle that people, systems, nodes, groups, entities, they can be connected to create an integrated set. The alterations within the network have wave effects in the whole.

[31] states that "nodes always compete for connections because the links represent survival in an interconnected world” (p.106). This competition is largely dulled within a personal learning network, but the supremacy of certain nodes over others is a reality. Nodes that successfully acquire better profiles will be more successful at acquiring additional connections. In a sense of learning, the likelihood that a concept of learning will be linked depends on how well it is currently linked. Nodes (can be fields, ideas, communities) that specialize and gain recognition by their expertise, it have greater chances of recognition, thus resulting in cross-pollination of communities learning. [32] weak ties are links or bridges that allow short connections between information.

Our small world networks are generally populated with people whose interests and knowledge are similar to ours. Finding a new job, as an example, often occurs through weak ties. This principle has great merit in the notion of serendipity, innovation, and creativity. Connections between disparate ideas and fields can create new innovations [33].

In the same time, as [32] note, people have much more knowledge than appears to be present in the information to which they have been exposed. Moreover, some knowledge domains contain vast numbers of weak interrelations that, if properly exploited, can greatly amplify learning by a process of inference. The value of pattern recognition and connecting learners own "small worlds of knowledge" are apparent in the exponential impact provided to personal learning.

Overview of connectivism Connectivism is the integration of principles explored by chaos, network, and complexity and self-organization theories. Learning is a process that occurs within nebulous environments of shifting core elements - not entirely under the control of the individual. Learning (defined as actionable knowledge) can reside outside of ourselves (within an organization or a database), is focused on connecting specialized information sets, and the connections that enable us to learn more are more important than our current state of knowing. The connectivism is conducted by the understanding that decisions are based on principles that change quickly.

For our purposes it is not important to define connectivism as a theoretical model, framework or theory. Its implications and functionality are the keys to its usefulness. Connectivism is an epistemological approach grounded in the interactions within networks [30] both inside the individual mind [34] and outside to the world, rather than to the individual memory of what to do (behaviourism), what to think (cognitivism) or how to make meaning (constructivism). It is becoming more 
influential and contentious of late due to its use as the epistemological basis for massive open online courses (MOOCs) [35]. [36,37] the original creator of a wiki page in a course on technology enhanced learning environments compared the four approaches (Figure 1).

We can glimpse a facet of behaviourism in the connectivist requirement that to know something, one must be able to do it; it shares the notions of neural networks with cognitivism; and it supports the group and community notions of social constructivism teaching [36].

Connectivism not only builds on the earlier notion of connectionism from computer science but also on the idea of situated cognition [38], that knowledge occurs not only in the minds of individuals; but rather, is supra- and transindividual and also exists within and between groups. Its heritage also includes that of collective intelligence [38], which is the idea that through the use of collaborative technologies people can carry out a task as if the group were a single organism rather than individual agents.

Based on such thinking, we hold the view that the collective knowing of a group of people is greater than any one individual's knowledge. Moreover, group knowledge is knowledge not simply in symbolic or poetic ways but in literal ways, in that it can be defined as the set of connections formed by action or experience [30].

Knowledge is inherently distributed and relies on the presence of networks. [25] without which it could not exist. [39] concurs with [30] that "knowledge" is emergent from an individual's learning network as connections are recognized, that is, "learning occurs as connections are made" (p. 676).

\begin{tabular}{|l|l|l|l|l|}
\hline \multicolumn{1}{|c|}{ Questions } & \multicolumn{1}{|c|}{ Behaviorism } & \multicolumn{1}{c|}{ Cognitivism } & \multicolumn{1}{c|}{ Constructivism } \\
\hline $\begin{array}{l}\text { How does learning } \\
\text { occur? }\end{array}$ & $\begin{array}{l}\text { Black box - observable behavior main } \\
\text { focus }\end{array}$ & $\begin{array}{l}\text { Structured, } \\
\text { computational }\end{array}$ & $\begin{array}{l}\text { Social, meaning created } \\
\text { by each learner } \\
\text { (personal) }\end{array}$ & $\begin{array}{l}\text { Distributed within a network, social, } \\
\text { technologically enhanced, recognizing } \\
\text { and interpreting patterns }\end{array}$ \\
\hline $\begin{array}{l}\text { What factors influence } \\
\text { learning? }\end{array}$ & Nature of reward, punishment, stimuli & $\begin{array}{l}\text { Existing schema, } \\
\text { previous experiences }\end{array}$ & $\begin{array}{l}\text { Engagement, } \\
\text { participation, social, } \\
\text { cultural }\end{array}$ & Diversity of network \\
\hline $\begin{array}{l}\text { What is the role of } \\
\text { memory? }\end{array}$ & $\begin{array}{l}\text { Memory is hardwiring of repeated } \\
\text { experiences - where reward and } \\
\text { punishment are mostinfluential }\end{array}$ & $\begin{array}{l}\text { Encoding, storage, } \\
\text { retrieval }\end{array}$ & $\begin{array}{l}\text { Prior knowledge remixed } \\
\text { to current context }\end{array}$ & $\begin{array}{l}\text { Adaptive patterns, representative of } \\
\text { current state, existing in networks }\end{array}$ \\
\hline $\begin{array}{l}\text { How does transfer } \\
\text { occur? }\end{array}$ & $\begin{array}{l}\text { Stimulus, response } \\
\text { What types of learning } \\
\text { are best explained by } \\
\text { this theory? }\end{array}$ & Task-based learning & $\begin{array}{l}\text { Duplicating knowledge } \\
\text { constructs of "knower" }\end{array}$ & Socialization \\
\hline
\end{tabular}

Figure 2. Comparison of four approaches to learning as [36]

Criticism at theory of connectivism. In spite of growing acknowledgement of connectivism as a useful approach to technology-enabled learning [40] some authors have leveled considerable criticism at it. Is Connectivism a new learning theory? As a fundamental criticism of connectivism, some argue that it is a pedagogical view, not a learning theory. [41], [42] believe that it is very similar to the older and more established actor-network theory. [43] criticized it by asking where the knowledge came from to create networks in the first place, the sort of argument often used by creationists to discount evolutionary theory of brain development. We hold the view that connectivism is an important new epistemology for education. [44] have argued on technical grounds that it is merely a phenomenon or a curriculum, rather than a novel learning theory.

According to [45], connectivism fails to qualify as a theory based on three criteria. They are: (i). Connectivism does not contribute to a theory or learning reform, due to its use of "language and slogans that are sometimes 'correct' but are too generalized to guide new practice at the level of how learning actually happens, (ii) "Connectivism does "contribute to a general world outlook," and (iii). Connectivism "misrepresents the current state of established alternative learning theories such as constructivism, behaviorism and cognitivism, so this basis for a new theory is also dubious" (p. 5-7).

\subsection{Connectivism principles}

The following, are the principles of the theory according to [25,29]: (i) Learning and knowledge rests in diversity of opinions (ii) Learning is a process of connecting specialized nodes or information sources (iii) Learning may reside in non-human appliances (iv) Capacity to know more is more critical than what is currently known (v) Nurturing and maintaining connections is needed to facilitate continual learning (vi) Ability to see connections between fields, ideas, and concepts is a core skill (vii) Currency (accurate, up-to-date knowledge) is the intent of all connectivist learning activities and (viii) Decision-making is itself a learning process. Choosing what to learn and the meaning of incoming information is seen through the lens of a shifting reality. While there is a right answer now, it may be wrong tomorrow due to alterations in the information climate affecting the decision.

For [25] social network analysis is an additional element in understanding learning models in a digital era "quantum theory of trust" which "explains not just how to recognize the collective cognitive capability of an organization, but how to cultivate and increase it”. Within social networks, hubs ${ }^{1}$ are well-connected people who are able to foster and maintain knowledge flow. Their interdependence results in effective knowledge flow, enabling the personal understanding of the state of activities from the organizational point of view. The starting point of connectivism is the individual. Personal knowledge is included in a network, which feeds to organizations and institutions, which in turn feed back to the network, and then continue to provide learning to individual. This cycle of knowledge development

\footnotetext{
${ }^{1}$ A hub is a device that allows to centralize the wiring of a network and to expand it. This means that the device receives a signal and repeats this signal by emitting it through its different ports.
} 
(personal to network to organization) allows apprentices to remain current in their field through the connections they have formed.

[25,29]: Connectivism also addresses the challenges that many corporations face in knowledge management activities. Knowledge that resides in a database needs to be connected with the right people in the right context in order to be classified as learning. Behaviorism, cognitivism, and constructivism do not attempt to address the challenges of organizational knowledge and transference.

Also information flow within an organization is an important element in organizational effectiveness. Creating, preserving, and utilizing information flow should be a key organizational activity. Knowledge flow can be likened to a river that meanders through the ecology of an organization. In certain areas, the river pools and in other areas it ebbs. The health of the learning ecology of the organization depends on effective nurturing of information flow.

Social network analysis is an additional element in understanding learning models in a digital era. Within social networks, hubs are well-connected people who are able to foster and maintain knowledge flow. Their interdependence results in effective knowledge flow, enabling the personal understanding of the state of activities organizationally.

\section{Reflexions and Conclusions}

1. Really what underlie are three great conceptions of learning: the behaviorist, the cognitive and the ecologicalcontextual. Possibly turning up to the psychologists, we would see more clearly than in this educational terminology. The most recent literature about educative research coincides in to mark only three main paradigms: positivist, interpretative and critic-reflexive. Besides of these three paradigms, recently the emergent paradigm is mentioned supported by different authors, including Guba, 1982; Howe, Kenneth 1988. Reichard, Ch and cook, T.D (1986) mentioned by [44].

2. The emergent paradigm, still in process of construction, is a possibility of integration with its own characteristics. Within each paradigm, previously mentioned, are built types of design and ways in which each conceives the mediate and immediate reality. Each one of them has limitations. This has led to what could be the emergence of a new one, which some authors have called 'paradigm of change'. Focus its objective on the application of knowledge to transform reality [25].

3. The greatest legacy of behaviorism consists of his scientific contributions about human behavior in their efforts to solve problems related to human behavior and behavior modeling, that even though they cannot be solved completely based on " award-punishment", teaches us that the use of reinforcements can strengthen appropriate behaviors and its disuse weaken the unwanted. The assignment of grades, rewards and punishments are also contributions of this theory [32].

4. Cognitive theory determines that: "learn" is the synthesis of form and content received by perceptions, which act in relative and personal way in each individual, and which in turn are influenced by their backgrounds, attitudes and individual motivations.
5. The connectivism presents a learning model that recognizes the tectonic shift in a society where learning is not an internal and individualist activity. How people works and function is altered when new tools are used. The field of education has been slow to recognize both the impact of the new learning tools as changes in the environment of what it means to learn. The connectivism provides understanding of the learning abilities and tasks necessary for the apprentices to thrive in a digital age. As knowledge continues to grow and evolve, access to what is needed is more important than what the learner currently possesses. [25].

6. Connectivism is a powerful idea. The central premise is that connections created with unusual nodes supports and intensifies existing large effort activities. This amplification of learning, knowledge and understanding through the extension of a personal network is the epitome of connectivism. A real challenge for any learning theory is to actuate known knowledge at the point of application. When knowledge, however, is needed, but not known, the ability to plug into sources to meet the requirements becomes a vital skill [46].

7. The connectivist view of learning as a network creation process significantly impacts the way learning is designed and developed. While the act of learning is seen as a function under the control of the learner, designers need to shift the focus to fostering the ideal ecology to permit learning to occur. By recognizing learning as a messy, nebulous, informal, chaotic process, we need to rethink how we design our instruction. Blogs, wikis, and other open, collaborative platforms are reshaping learning as a two-way process [46] Figure 3.

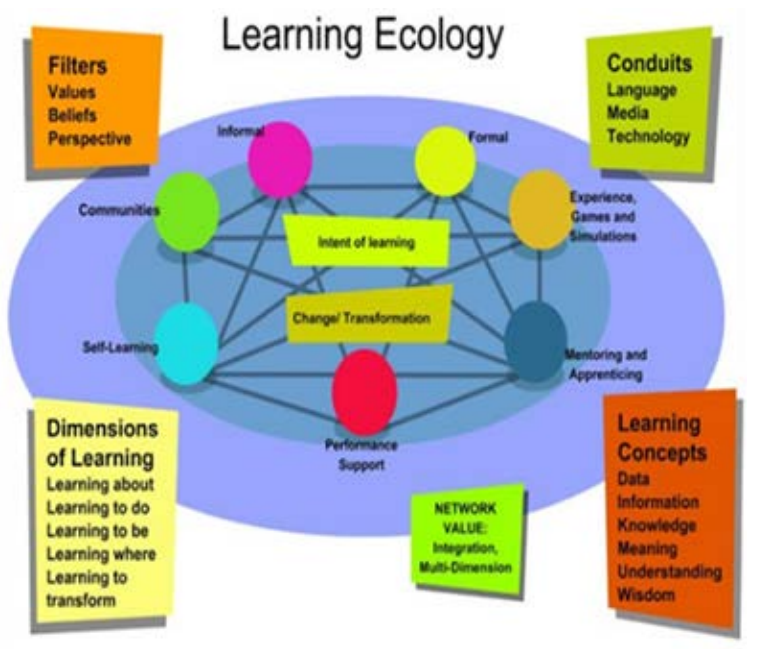

\section{Connectivism: Process of creating network}

Figure 3. Connectivism: A Learning Theory for the Digital Age as Simmons

\section{References}

[1] Borrás, I (1997) Internet for Teachers: Case study evaluation of a graduate level course. Educational Technology Research \& Development.

[2] Hernandez, G. (2002): Paradigms in educational psychology. Mexico: Polity Press.

[3] Kuhn, T. (2011). La Estructura de las Revoluciones Científicas. Fondo de Cultura Económica. México.

[4] Popper, K. (1994). The Myth of the Framework: In defence of science and rationality, London: Routledge. 
[5] Lakatos, I. (1980). The methodology of scientific research programmes: Volume 1: Philosophical papers (Vol. 1). Cambridge University Press.

[6] Guba, E \& Lincoln, Y. (1981) Effective Evaluation. San Francisco.

[7] Guba, E. G., \& Lincoln, Y. S. (1994). Competing paradigms in qualitative research. Handbook of qualitative research, 2, 163-194.

[8] Cantrell, D. C. (1993). Alternative paradigms in environmental education research: The interpretive perspective. Alternative paradigms in environmental education research, 8, 81-104.

[9] Chambers, N. (1999). Close encounters: the use of critical reflective analysis as an evaluation tool in teaching and learning. Journal of advanced nursing, 29(4), 950-957.

[10] The Design-Based Research Collective. (2003). Design-based research: An emerging paradigm for educational inquiry. Educational Researcher, 5-8.

[11] Cook, T. D., \& Campbell, D. T. (1979). Quasi- experimentation: Design and analysis issues for field settings. Chicago: RandMcNally.

[12] Brophy, J., \& Good, T. L. (1984). Teacher Behavior and Student Achievement. Occasional Paper No. 73.

[13] Brophy, J. (1999). Toward a model of the value aspects of motivation in education: Developing appreciation for.. Educational psychologist, 34(2), 75-85.

[14] Montero (1990) Teacher behaviors and learning outcomes: analysis of some relationships. In Carretero, M., Palacios, G. and Machesi, A. (Eds).

[15] Herrero, C (2006) Teacher education in a global society. Retrieved March 18, 2008 educational http://seer.ucg.br/index.php/ / article / view / 157/121.

[16] Domjan, M. (2014). The principles of learning and behavior. Cengage Learning.

[17] van Merriënboer, J. J., \& de Bruin, A. B. (2014). Research paradigms and perspectives on learning. In Handbook of Research on Educational Communications and Technology (pp. 21-29). Springer New York.

[18] Vygotsky, L. (1979) The development of higher psychological processes. Barcelona: Grijalbo.

[19] Zhang, C., Li, D., Yang, J., \& Yong, A. (2014). Human cognitive paradigm and its application in semi-supervised learning. OptikInternational Journal for Light and Electron Optics, 125(3), 11781184.

[20] Powell, K. C., \& Kalina, C. J. (2009). Cognitive and social constructivism: developing tools for any effective classroom. Education, 130(2).

[21] Morin, E (2008) Complex Thinking Retrieved March 1, 2008 http://www.pensamientocomplejo. com.ar / Peter, S and Pellegrini, A (2000) Higher Education Psychologyof Themes.

[22] Driscoll, M (2002). How People Learn (and What Technology Might Have To Do with It). ERIC Digest.

[23] Driscoll, M. P., \& Driscoll, M. P. (2005). Psychology of learning for instruction.

[24] Stephenson, K., (Internal Communication, no. 36) What Knowledge Tears Apart, Networks Make Whole. Retrieved December 10, 2004 from http://www.netform.com/html/icf.pdf.

[25] Siemens, George. "Connectivism: A learning theory for the digital age (2004)." elearnspace. Disponível em: $<$ http://www. ingedewaard. net/papers/connectivism/2005_siemens_ALearningTheoryF orTheDigitalAge. pdf $>$. Acesso em 5 (2012).

[26] Kellert, S. H. (1994). In the wake of chaos: Unpredictable order in dynamical systems. University of Chicago press.

[27] McBride, N. (2005). Chaos theory as a model for interpreting information systems in organizations. Information Systems Journal, 15(3), 233-254.
[28] Walsham, G. (2005). Learning about being critical. Information Systems Journal, 15(2), 111-117.

[29] Downes, S. (2005). Feature: E-learning 2.0. Elearn magazine, 2005(10), 1.

[30] Downes, Stephen (2012). "Connectivism and Connective Knowledge: essays on meaning and learning networks." National Research Council Canada, http://www. downes. ca/files/books/Connective_Knowledge-19May2012. pdf

[31] Barabási, A. L., (2002) Linked: The New Science of Networks, Cambridge, MA, Perseus Publishing.

[32] Landauer, T. K., \& Dumais, S. T. (1997). A solution to Plato's problem: The latent semantic analysis theory of acquisition, induction, and representation of knowledge. Psychological review, 104(2), 211

[33] Kee, K. F., Sparks, L., Struppa, D. C., \& Mannucci, M. (2013). Social groups, social media, and higher dimensional social structures: A simplicial model of social aggregation for computational communication research. Communication Quarterly, 61(1), 35-58.

[34] Spitzer, M. (1999). The mind within the net: Models of learning, thinking, and acting. Cambridge, MA.MIT Press.

[35] Bell, F. (2011). Connectivism: Its place in theory-informed research and innovation in technologyenabled learning. International Review of Research in Open and Distance Learning, 12(3), 98-118.

[36] Slavich, G. M., \& Zimbardo, P. G. (2012). Transformational teaching: Theoretical underpinnings, basic principles, and core methods. Educational Psychology Review, 24(4), 569-608.

[37] Ireland, T. (2007). Situating connectivism [Design Wiki]. ETEC 510: Design of technology-supported learning environments. University of British Columbia. Retrieved from: http://etec.ctlt.ubc.ca/510wiki/Situating_Connectivism.

[38] Lave. J., \& Wenger, E. (1991). Situated learning: Legitimate peripheral participation. New York and Cambridge, UK: Cambridge University Press.

[39] Dunaway, M. K. (2011). Connectivism: learning theory, and pedagogical practice for networked information landscapes. Reference Services Review, 39(4), 675-685.

[40] Cormier, D. (2008). Rhizomatic education: Community as curriculum. Innovate, 4(5). Retrieved from http://www.innovateonline.info/index.php?view=article\&id=550.

[41] Bell, F. (2011). Connectivism: Its place in theory-informed research and innovation in technology enabled learning. International Review of Research in Open and Distance Learning, 12(3), 98-118.

[42] Anderson, T., \& Dron, J. (2011). Three generations of distance education pedagogy. International Review of Research in Open and Distance Learning, 12(3), 80-97.

[43] Wade, M. C. (2012). A critique of connectivism as a learning theory [Web log post]. Retrieved from Cybergogue: Doing is Learning http://cybergogue.blogspot.nl/2012/05/critique-of-connectivismaslearning.html.

[44] Verhagen, P. (2006, November). Connectivism: a new learning theory?. elearning, Retrieved November 4, 2008, from http://www.surfspace.nl/nl/Redactieomgeving/ Publicaties/Documents/Connectivism\%20a\%20new\%20theory.pdf

[45] Kerr, B. (December 2006). A challenge to connectivism. Retrieved November 11, 2008, from http://billkerr2.blogspot.com/2006/12/challenge-toconnectivism.htm.

[46] García, I (2008). Connectivity theory as an emerging solution strategies-innovative learning (e-learning) - International Conference on Education for Higher Education Innovation: Convergence to this process, Madrid, 22-24 October. 